\title{
Critical care at the end of life: a population- level cohort study of cost and outcomes
}

\author{
Dipayan Chaudhuri ${ }^{1}$, Peter Tanuseputro ${ }^{2,3}$, Brent Herritt ${ }^{1}$, Gianni D'Egidio ${ }^{1}$, Mathieu Chalifoux ${ }^{1}$ \\ and Kwadwo Kyeremanteng ${ }^{1,4^{*}}$ (i)
}

\begin{abstract}
Background: Despite the high cost associated with ICU use at the end of life, very little is known at a population level about the characteristics of users and their end of life experience. In this study, our goal was to characterize decedents who received intensive care near the end of life and examine their overall health care use prior to death.

Methods: This was a retrospective cohort study that examined all deaths in a 3-year period from April 2010 to March 2013 in Ontario, Canada. Using population-based health administrative databases, we examined healthcare use and cost in the last year of life.

Results: There were 264,754 individuals included in the study, of whom 18\% used the ICU in the last 90 days of life; 34.5\% of these ICU users were older than 80 years of age and $53.0 \%$ had more than five chronic conditions. The average cost of stay for these decedents was CA\$15,511 to CA\$25,526 greater than for those who were not admitted to the ICU. These individuals also died more frequently in hospital (88.7\% vs 36.2\%), and spent more time in acute-care settings (18.7 days vs. 10.5 days).

Conclusions: We showed at a population level that a significant proportion of those with ICU use close to death are older, multi-morbid individuals who incur significantly greater costs and die largely in hospital, with higher rates of readmission, longer lengths of stay and higher rates of aggressive care.
\end{abstract}

Keywords: Palliative care, Terminal care, Costs and cost analysis

\section{Background}

In Ontario, Canada, $98.9 \%$ of individuals access health care at least once in their last year of life costing the healthcare system, on average, CA $\$ 4.7$ billion annually, or approximately $10 \%$ of the annual healthcare budget $[1,2]$. Hospitalizations alone account for approximately $43 \%$ of those costs, with $20 \%$ of those costs as a result of at least one ICU visit. Current guidelines from the Society of Critical Care Medicine state that "in general, ICUs should be reserved for those patients with reversible medical conditions who have reasonable prospect of substantial recovery." [3]. A prospective cross-sectional study conducted in a Canadian teaching hospital in 2014 suggested that in $37 \%$ of patients admitted to the ICU, at least one member of the care team believed that a

\footnotetext{
* Correspondence: kwadwo77@gmail.com

University of Ottawa, Ottawa, ON, Canada

${ }^{4}$ The Ottawa Hospital General Campus, 501 Smyth Road, Ottawa, ON K1H

8L2, Canada

Full list of author information is available at the end of the article
}

patient was being given excessive or inappropriate care in the ICU [4]. Many studies suggest that advance care planning and palliative care interventions rather than ICU admissions in older, critically ill or dying patients reduce healthcare costs and provide patients with a better quality of life in the time they have left $[3,5-7]$. Despite this evidence, in both the USA and Canada, ICU use has been increasing over time $[1,5]$.

In this study, we describe the use of ICU towards the end of life in Ontario, a province with over 13 million residents and near-universal health care [8]. Specifically, our goal was first to characterize decedents who received intensive care in the last few months, weeks and days of life. We then examined the costs associated with caring for those with ICU stays near the end of life, across a comprehensive set of healthcare sectors, including inpatient, outpatient and long-term care. It is expected although never previously shown - that the cost associated with acute care stays among ICU users will 
dominate overall cost incurred across all sectors. Finally, we examined the dying experience of those with an ICU stay, including their location of death, rates of hospitalization and readmission, and rates of aggressive treatment. We compared this to the population that did not stay in the ICU.

While a few studies have examined ICU use at the end of life [9-11], this study, examined the ICU population and healthcare cost in greater detail - across a broad range of health sectors, and at a population level. Furthermore, it characterizes the typical ICU decedent in a large heterogeneous population and illustrates what their dying experience might be like, thus, allowing for possible areas of focus where palliative care and end-of-life planning can play a larger role in improving patients' end-of-life outcomes.

\section{Methods}

We conducted a retrospective cohort study examining healthcare use and cost incurred by decedents in their last 90 days of life. We captured all deaths in a 3-year period, from 1 April 2010 to 31 March 2013 (fiscal year (FY) 2010/11 to 2012/13) in Ontario, Canada. Using encrypted health card numbers as unique identifiers, records of healthcare use and costs were linked across various administrative databases. This study has been approved by the research ethics board at the Institute for Clinical Evaluative Sciences, at Sunnybrook Health Sciences Centre and at Ottawa Hospital Research Institute. No written consent was obtained; all data were encrypted using health card numbers as unique identifiers. Thus, all records used were de-identified and anonymized.

\section{Data sources and definitions}

Deaths were identified using the Ontario Registered Persons Database (RPDB). The databases used to identify healthcare use are outlined in Additional file 1. We captured all decedents with a death date in the RPDB in our time period. We described the age and sex distribution of these individuals, the details being captured in the RPDB one year prior to death. The decedents' socioeconomic status was measured using their neighborhood income one year prior to death. Following well-established methods, both neighborhood income and rurality were captured by linking to Statistics Canada census data using postal codes [12]. Decedents were further subdivided into quartiles using Aggregated Diagnosis Groups (ADG) and Adjusted Clinical Groups (ACG) scores. These algorithms were developed to predict the healthcare resource utilization that a patient may require as a result of their comorbidities, and have been shown to be strong predictors of one-year mortality in general ambulatory populations [13].
Intensive care use during a hospital admission in the last 3, 14, and 90 days of life were captured in the Canadian Institute for Health Information (CIHI) Discharge Abstract Database. We looked at the variables SCUSCU6, which indicates codes when the patient is admitted into the ICU. Any of the non 9X codes occurring in the last 3,14, and 90 days of life indicated that hospitalizations were ICU-related. We included stays in all types of ICU, including medical, surgical, and trauma ICUs. During these time periods, decedents were categorized as having no admission into hospital, having at least one admission but without an ICU stay, or having at least one admission with an ICU stay.

\section{Statistical analysis}

All records of healthcare use were retrieved that had been paid for by the provincial Ministry of Health and Long Term Care (MOHLTC) in the last year of life. The cost associated with each record was estimated using costing methods developed for health administrative data described elsewhere [14]. Briefly, we have taken a payer (MOHLTC) costing perspective, using person-level healthcare expenditure that accounts for data for health care utilization and cost information per use. Cost information for sectors (e.g., hospitals, complex continuing care, rehabilitation) that have global budgets (e.g., by institution or by health region) are determined using a top-down approach through case-mix methodology. Sectors that have fee payments associated with each use (e.g., drug cost or cost paid out to the physician) have costs estimated directly. All costs were expressed in 2013 Canadian dollars; we inflated past costs using the healthcare-specific yearly Consumer Price Index reported by Statistics Canada. The health sector cost for the population was the sum of all costs among decedents captured within each respective sector. We also examined total cost within each sector by month prior to death.

All statistical tests were two-tailed and $p=0.05$ was used to determine statistical significance. We used SAS 9.3 (SAS Institute Inc., Cary, NC, USA) for all analyses. We categorized our population by background demographic information such as age, sex, neighborhood income, rurality, primary core model, chronic conditions, and ADG quartile, and compared these across ICU users, non-ICU users, and all comers. Neighborhood income and rurality were derived from well-established methods from each decedent's postal code of residence one year prior to death. Chronic conditions were derived from previously defined cohorts at the Institute for Clinical Evaluative Sciences, often based on previous records of healthcare use (e.g., physician claims, hospital visits, and medications), and at times validated. We then analyzed breakdowns of where costs occurred across different healthcare sectors, including acute (inpatient and emergency department), chronic (long-term care, 
complex, continuing care, home care, and rehabilitation) and outpatient care (clinics, physician billings, laboratory costs, drugs/devices, and non-physician OHIP billings) and compared these costs against ADG quartiles.

\section{Patient outcomes}

We examined certain key health outcomes, such as location of death, length of stay in various places of care, readmission rates, cardiopulmonary resuscitation (CPR) rates and feeding tube insertion rates and examined how they differed amongst ICU users and non-ICU users. Location of death was determined by observing records of admissions in acute care, complex continuing care, longterm care, and rehabilitation facilities. All other deaths were classified as deaths in the community, and were broken down into those that occurred with or without home care support. The numbers of days spent in each of these settings were also observed in the last 90 days of life.

\section{Results}

\section{General demographics}

Overall, 264,754 individuals were included in the study, of whom 47,763 individuals (18\%) were admitted to the ICU at least once in the last 90 days of life. The highest absolute numbers of ICU users were universally within the $80-89$ years age range (Table 1 ). A larger percentage of ICU users lived in poorer neighborhoods and were rostered to a family physician. Individuals who stayed in the ICU at the end of life also had a greater disease burden, with a larger proportion in the third and fourth ADG quartiles when compared to the non-ICU-stay group (Table 1). Lastly, a larger proportion of individuals who stayed in the ICU had congestive heart failure (CHF), peripheral vascular disease (PVD), acute myocardial infarction, diabetes mellitus, asthma, stroke, or renal disease. Conversely, among the no-ICU population significantly larger proportions of individuals had dementia or cancer (Table 1).

\section{Costs of ICU stay}

Decedents who stayed in the ICU in the last 90 days of their life incurred much higher costs than those who did not (Fig. 1, Table 2). For example, in the first ADG quartile this amounted to an average cost difference of approximately CA $\$ 15,101$ (139\% increases) and in the fourth ADG quartile, the difference was CA $\$ 25,765$ (81\% increase). Most of this cost difference could be attributed to differences in inpatient costs - CA $\$ 15,511$ (472\% increase) in the first ADG quartile and CA $\$ 25,526$ (144\% increase) in the fourth ADG quartile (Table 2).

As the disease burden increased, the average cost across ADG quartiles in the ICU group increased by
CA $\$ 31,646$ (122\%) and in the non-ICU group by CA\$20,983 (193\%). Most of this increase could be attributed to inpatient costs, with an average cost increase, across ADG quartiles, of CA $\$ 24,433$ in the ICU group and $\mathrm{CA} \$ 14,418$ in the non-ICU group.

\section{Health outcomes}

Individuals who were admitted to ICU in the last 90 days of life died in acute care by a far larger proportion than those who did not $(88.7 \%$ vs. $36.2 \%)$ (Table 3, Table 4). Furthermore, they were readmitted to hospital more $(40.22 \%$ vs. $16.89 \%)$ and $11.5 \%$ were readmitted to the ICU. They also spent more time in institutions (21.4 days vs. 14.8 days), specifically in acute care (18.7 days vs. 10.5 days). In addition, they also had higher rates of feeding tube insertions and CPR performed.

\section{Discussion}

Three important observations can be made as a result of this study. The first is that despite the general notion that a significant proportion of older, frail and multi-morbid individuals close to death do not do well in the ICU [15-18], we showed that at a population level, a significant proportion of those with ICU use when close to death are actually older and multimorbid. Second, we showed the significant additional cost incurred by the healthcare system when decedents are admitted to an ICU, especially in relation to inpatient services. Last, we demonstrated that decedents with ICU use at the end of life die largely in hospital, with higher rates of readmission, longer lengths of stay, and higher rates of aggressive care including CPR and feeding tube insertion.

This is not the first study to examine use of ICU at the end of life. Angus et al. [9] conducted an analysis of ICU use in 1999 of all decedents in all non-federal hospitals in six states in the USA. They demonstrated similar rates of ICU use (22\%) at the end of life, and when factoring in inflation they identified similar costs. Wunsch et al. [10] conducted a study examining differences in ICU use at the end of life between England and the USA. While the USA once again had similar ICU use to that identified in this study, the ICU use was significantly lower in England. Another study, performed in the Netherlands [11] compared terminally ill patients with and without cancer, showing that patients dying due to non-cancerous diseases were twice as likely to be admitted to the ICU. This study supports this body of evidence with more recent data and provides additional information on the differences in ICU use and cost, based on factors such as burden of disease. Furthermore, it provides much greater detail on the breakdown of 
Table 1 Characteristics and demographics of decedents in the last 90 days of life

\begin{tabular}{|c|c|c|c|}
\hline & $\begin{array}{l}\text { Number of } \\
\text { decedents with } \\
\text { ICU use in last } \\
90 \text { days } \\
\text { of life }(n,(\%)) \\
(\mathrm{N}=47,763)\end{array}$ & $\begin{array}{l}\text { Number of decedents } \\
\text { with no ICU in } \\
\text { last } 90 \text { days } \\
\text { of life }(n,(\%)) \\
(\mathrm{N}=216,991)\end{array}$ & $\begin{array}{l}\text { Total number } \\
\text { of decedents } \\
(n,(\%)) \\
(\mathrm{N}=264,754)\end{array}$ \\
\hline \multicolumn{4}{|l|}{ Age, years } \\
\hline 0-19 & $1242(2.6)$ & $2841(1.3)$ & $4083(1.5)$ \\
\hline $20--39$ & $1180(2.5)$ & $3798(1.8)$ & $4978(1.9)$ \\
\hline $40-49$ & $2054(4.3)$ & $6066(2.8)$ & $8120(3.1)$ \\
\hline $50-59$ & $5132(10.7)$ & $15,397(7.1)$ & $20,529(7.8)$ \\
\hline $60-69$ & $8852(18.5)$ & $26,594(12.3)$ & $35,446(13.4)$ \\
\hline 70-79 & $12,836(26.9)$ & $42,626(19.6)$ & $55,462(21.0)$ \\
\hline $80-89$ & $13,625(28.5)$ & $75,332(34.7)$ & $88,957(33.6)$ \\
\hline $90+$ & $2842(6.0)$ & $44,337(20.4)$ & $47,179(17.8)$ \\
\hline \multicolumn{4}{|l|}{ Sex } \\
\hline Female & 20,919 (43.8) & $11,4715(52.9)$ & $\begin{array}{l}135,634 \\
(51.2)\end{array}$ \\
\hline Male & $26,844(56.2)$ & $102,276(47.1)$ & $\begin{array}{l}129,120 \\
(48.8)\end{array}$ \\
\hline \multicolumn{4}{|l|}{ Income quintile } \\
\hline Lowest & $11,212(23.5)$ & $48,853(22.5)$ & $60,065(22.7)$ \\
\hline Low & $10,123(21.2)$ & $44,721(20.6)$ & $54,844(20.7)$ \\
\hline Middle & 8964 (18.8) & $41,507(19.1)$ & $50,471(19.1)$ \\
\hline High & 8687 (18.2) & $40,525(18.7)$ & $49,212(18.6)$ \\
\hline Highest & 7902 (16.5) & $38,544(17.8)$ & $46,446(17.5)$ \\
\hline Missing & 875 (1.8) & $2841(1.3)$ & $3716(1.4)$ \\
\hline \multicolumn{4}{|c|}{ Chronic conditions } \\
\hline Osteoarthiritis & $23,278(48.7)$ & $106,178(48.9)$ & $\begin{array}{l}12,9456 \\
(48.9)\end{array}$ \\
\hline $\begin{array}{l}\text { Arthiritis - } \\
\text { other }\end{array}$ & $2178(4.6)$ & $8243(3.8)$ & $10,421(3.9)$ \\
\hline Cancer & $18,045(37.8)$ & $96,854(44.6)$ & $\begin{array}{l}114,899 \\
(43.4)\end{array}$ \\
\hline Arrythmia & $13,728(28.7)$ & $47,338(21.8)$ & $61,066(23.1)$ \\
\hline Dementia & $5790(12.1)$ & $69,566(32.1)$ & $75,356(28.5)$ \\
\hline Depression & $9426(19.7)$ & $44,674(20.6)$ & $54,100(20.4)$ \\
\hline Osteoporosis & $3258(6.8)$ & $18,448(8.5)$ & $21,706(8.2)$ \\
\hline Renal & $16,520(34.6)$ & $46,413(21.4)$ & $62,933(23.8)$ \\
\hline Stroke & 8349 (17.5) & $32,992(15.2)$ & $41,341(15.6)$ \\
\hline PVD & $18,579(38.9)$ & $67,080(30.9)$ & 85,659 (32.4) \\
\hline Asthma & 8895 (18.6) & $32,340(14.9)$ & $41,235(15.6)$ \\
\hline $\mathrm{CHF}$ & $20,856(43.7)$ & $68,005(31.3)$ & 88,861 (33.6) \\
\hline COPD & $14,711(30.8)$ & $51,372(23.7)$ & $66,083(25.0)$ \\
\hline Hypertension & $36,370(76.2)$ & $159,720(73.6)$ & $\begin{array}{l}196,090 \\
(74.1)\end{array}$ \\
\hline $\begin{array}{l}\text { Diabetes } \\
\text { mellitus }\end{array}$ & $20,113(42.1)$ & $73,022(33.7)$ & $93,135(35.2)$ \\
\hline AMI & 5035 (10.5) & 7765 (3.6) & $12,800(4.8)$ \\
\hline
\end{tabular}

Table 1 Characteristics and demographics of decedents in the last 90 days of life (Continued)

\begin{tabular}{clll}
\hline ADG quartiles & & & \\
1st quartile & $5069(10.6)$ & $61,633(28.4)$ & $66,702(25.2)$ \\
2nd quartile & $13,096(27.4)$ & $53,853(24.8)$ & $66,949(25.3)$ \\
3rd quartile & $14,314(30.0)$ & $52,896(24.4)$ & $67,210(25.4)$ \\
4th quartile & $15,284(32.0)$ & $48,609(22.4)$ & $63,893(24.1)$ \\
\hline
\end{tabular}

PVD peripheral vascular disease, $C H F$ congestive heart failure, COPD chronic obstructive pulmonary disease, $A D G$ Aggregated Diagnosis Groups, $A M I$ acute myocardial infarction

costs at the end of life, and on the type of care provided at the end of life, to help identify areas where possible interventions could take place.

Many previous studies have shown that the elderly, with or without significant comorbidities often do worse in the ICU, both during their stay and after discharge [15-18]. This includes having increased mortality, increased morbidity, decreased quality of life, and decreased functional status $[15,16]$. Our study also shows that a larger proportion of decedents who used the ICU had a greater disease burden when compared to decedents not using the ICU. While we cannot comment on the appropriateness of ICU admission in a descriptive retrospective study looking only at decedents, previous studies have shown that individuals with greater disease burden not only increase healthcare expenditures, but they also have higher mortality rates [13, 19-24], longer lengths of stay [23], higher readmission rates to the ICU in the same stay [22], and even perceive their quality of life to be worse after discharge from the ICU [21].

ICU care is also expensive, making up $0.5-1.0 \%$ of the Ontario gross domestic product (GDP) [25]. We clearly showed the significantly greater cost that ICU decedents incur at the end of life. Additionally, multiple studies show that most individuals do not wish for lifeprolonging, intensive care towards the end of life [2631]. While some elderly individuals can benefit from an ICU stay [18], this study suggests the need for careful thought and more research into appropriate ICU admissions at the end of life.

When it comes to end-of-life planning, most individuals prefer dying at home, with comfort care, rather than life-prolonging treatments [27-29]. Also, previous studies have shown that increased home care in the community leads to fewer hospitalizations and decreased costs in acute care [30]. Our study shows a significant discrepancy in location of death, length of hospital stay, place of stay, readmission rates, and rates of aggressive care amongst decedents who do and do not use the ICU. This may indicate potential missed opportunities for more dignified deaths through palliative care and early goals-of-life discussions. 


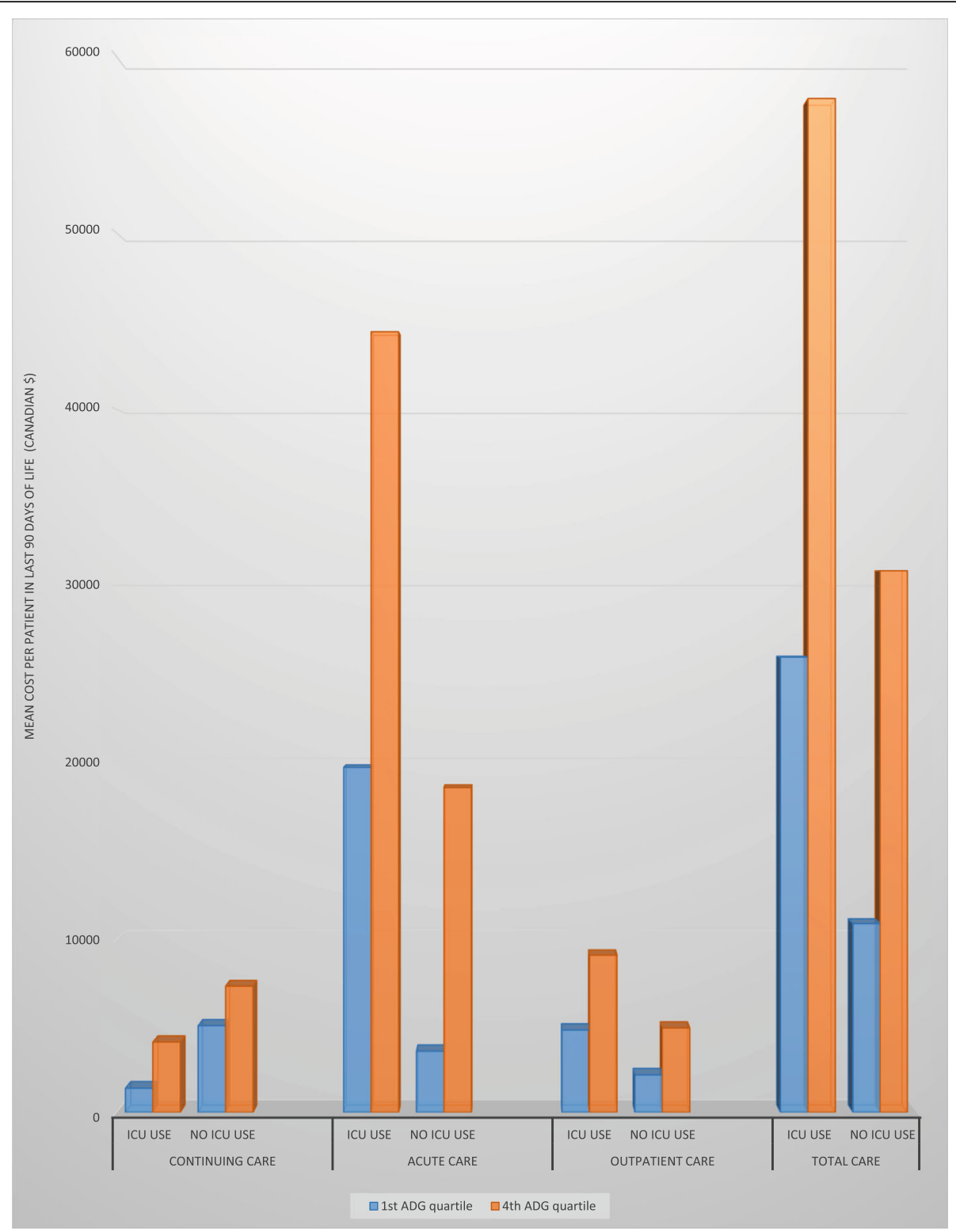

Fig. 1 Healthcare costs in the last 90 days of life. Average healthcare cost per decedent in the last 90 days of life when distributed across healthcare sectors (continuing care, acute care and outpatient care), ICU use and burden of disease (represented by the first and fourth aggregated diagnosis group ( $A D G$ ) quartiles). Patients in the first ADG quartile have the lowest burden of disease and those in the fourth ADG quartile have the highest burden of disease

There are a few limitations to this study [32]. First, since we only examined patients who died, we could not perform an unbiased analysis of whether patients are appropriately admitted to ICU at the end of life, as we did not have any information on the proportion of the population that survived. Thus, any conclusions made regarding the appropriateness of ICU admission based on a specific demographic or identifying characteristic can be biased either way, based on the outcomes of patients in that demographic who did not die. Second, in our broad population conclusions on the appropriateness of ICU admission and the quality of the end of life experience require additional details and may vary by subgroups within the population. For example, while the ICU group did have higher rates of death in an acute care setting and of aggressive care measures being performed, we cannot conclusively comment on whether this was appropriate without having additional information, such as the reason for admission, the underlying demographics, and the speed of disease progression in the patients who received these interventions. Nevertheless, given the large proportion of those admitted to ICU with 
Table 2 Mean cost in last 90 days of life across health care sectors (2013 Canadian dollars)

\begin{tabular}{|c|c|c|c|c|c|c|c|c|c|c|c|c|}
\hline \multirow[b]{2}{*}{ ADG RANK } & \multicolumn{4}{|c|}{$\begin{array}{l}\text { Decedents with ICU stay (CAD \$) } \\
(N=47763)\end{array}$} & \multicolumn{4}{|c|}{$\begin{array}{l}\text { Decedents without ICU stay (CAD \$) } \\
(N=216991)\end{array}$} & \multicolumn{4}{|c|}{$\begin{array}{l}\text { All decedents (CAD \$) } \\
(N=264754)\end{array}$} \\
\hline & Q1 & Q2 & Q3 & Q4 & Q1 & Q2 & Q3 & Q4 & Q1 & Q2 & Q3 & Q4 \\
\hline \multicolumn{13}{|c|}{ Continuing Care Sectors } \\
\hline Long-term Care & 248.70 & 353.29 & 539.78 & 866.63 & 3123.18 & 2615.20 & 2591.00 & 2841.76 & 2904.73 & 2172.74 & 2154.14 & 2369.28 \\
\hline $\begin{array}{l}\text { Complex } \\
\text { Continuing Care }\end{array}$ & 348.79 & 521.96 & 827.13 & 1246.48 & 854.85 & 1632.18 & 2108.96 & 2934.99 & 816.39 & 1415.01 & 1835.97 & 2531.08 \\
\hline Home Care & 619.95 & 854.89 & 1035.64 & 1179.18 & 1002.95 & 1804.33 & 1953.47 & 1936.17 & 973.84 & 1618.61 & 1758.00 & 1755.09 \\
\hline Rehabilitation & 199.12 & 474.00 & 604.16 & 846.28 & 90.75 & 281.94 & 395.07 & 611.45 & 98.98 & 319.51 & 439.60 & 667.62 \\
\hline \multicolumn{13}{|l|}{ Acute Care Sectors } \\
\hline Inpatient & 18793.73 & 27287.33 & 35475.67 & 43227.11 & 3282.07 & 9420.51 & 13390.41 & 17700.34 & 4460.87 & 12915.46 & 18094.00 & 23806.66 \\
\hline $\begin{array}{l}\text { Emergency } \\
\text { Department }\end{array}$ & 924.27 & 1046.35 & 1111.73 & 1163.73 & 317.33 & 638.54 & 779.46 & 873.87 & 363.45 & 718.31 & 850.23 & 943.21 \\
\hline \multicolumn{13}{|c|}{ Outpatient Care Sectors } \\
\hline Outpatient clinics & 392.43 & 800.53 & 1361.90 & 1311.71 & 463.46 & 1020.97 & 1100.33 & 987.50 & 458.06 & 977.85 & 1156.03 & 1065.05 \\
\hline Physician Billings & 3988.53 & 5040.29 & 6086.83 & 6879.41 & 996.51 & 2004.52 & 2458.43 & 2797.10 & 1223.89 & 2598.35 & 3231.19 & 3773.64 \\
\hline $\begin{array}{l}\text { Non-physician } \\
\text { Billings (OHIP) }\end{array}$ & 17.52 & 22.07 & 29.61 & 42.02 & 94.66 & 88.91 & 93.69 & 104.83 & 88.80 & 75.84 & 80.04 & 89.81 \\
\hline Laboratory (OHIP) & 32.11 & 49.58 & 56.68 & 63.35 & 40.15 & 57.52 & 65.97 & 77.46 & 39.54 & 55.97 & 63.99 & 74.09 \\
\hline Drugs/Devices & 402.64 & 572.71 & 745.36 & 788.34 & 600.16 & 883.20 & 965.75 & 983.36 & 585.15 & 822.47 & 918.81 & 936.71 \\
\hline Total Costs & 25967.80 & 37023.00 & 47874.49 & 57614.23 & 10866.04 & 20447.83 & 25902.55 & 31848.83 & 12013.70 & 23690.12 & 30582.01 & 38012.23 \\
\hline
\end{tabular}

advanced age and multiple comorbidities, there are potentially a significant number of inappropriate admissions and possible areas of intervention where healthcare costs could be reduced and the quality of the end of life experience may improve.

\section{Conclusions}

In summary, our findings indicate that the majority of individuals admitted to ICU at the end of life are elderly and burdened by chronic illness. The existing medical literature indicates that this is the exact type of population

Table 3 Health outcomes of decedents in the last 90 days of life

\begin{tabular}{|c|c|c|c|}
\hline & $\begin{array}{l}\text { Number of decedents with ICU use in last } \\
90 \text { days of life }(n,(\%))(N=47,763)\end{array}$ & $\begin{array}{l}\text { Number of decedents with no ICU use in last } \\
90 \text { days of life }(n,(\%))(N=216,991)\end{array}$ & $\begin{array}{l}\text { Total number of decedents } \\
(n,(\%))(N=264,754)\end{array}$ \\
\hline \multicolumn{4}{|l|}{ Location of death } \\
\hline Acute care & $42,381(88.7)$ & $78,602(36.2)$ & $120,983(45.7)$ \\
\hline Long term care & 756 (1.6) & $45,409(20.9)$ & $46,165(17.4)$ \\
\hline $\begin{array}{l}\text { Complex } \\
\text { continuing care }\end{array}$ & $1746(3.7)$ & $18513(8.5)$ & $20,259(7.7)$ \\
\hline $\begin{array}{l}\text { Home while } \\
\text { receiving home care }\end{array}$ & $1272(2.7)$ & $26,644(12.3)$ & $27,916(10.5)$ \\
\hline Rehabilitation & $81(0.2)$ & $340(0.2)$ & $421(0.2)$ \\
\hline Other & $1527(3.2)$ & $47,483(21.9)$ & $49,010(18.5)$ \\
\hline \multicolumn{4}{|c|}{ Readmission in last 90 days } \\
\hline To hospital & $19,211(40.2)$ & $36,649(16.9)$ & $55,860(21.1)$ \\
\hline To ICU & $5491(11.5)$ & $\mathrm{N} / \mathrm{A}$ & $5491(2.1)$ \\
\hline \multicolumn{4}{|c|}{ Feeding tube during hospitalization } \\
\hline No & $45,746(95.8)$ & 215,097 (99.1) & $260,843(98.5)$ \\
\hline Yes & $2017(4.2)$ & $1894(0.9)$ & $3911(1.5)$ \\
\hline \multicolumn{4}{|c|}{ Heart resuscitation during hospitalization } \\
\hline No & $42,265(88.5)$ & $214,667(98.9)$ & $256,932(97.1)$ \\
\hline Yes & $5498(11.5)$ & $2324(1.1)$ & 7822 (3.0) \\
\hline
\end{tabular}


Table 4 Average length of stay in various places of care in the last 90 days of life

\begin{tabular}{|c|c|c|c|}
\hline & $\begin{array}{l}\text { Average } \\
\text { length of stay } \\
\text { amongst } \\
\text { ICU users } \\
\text { (days) }(\mathrm{N}=47,763)\end{array}$ & $\begin{array}{l}\text { Average length } \\
\text { of stay amongst } \\
\text { non-ICU users } \\
\text { (days) }(\mathrm{N}=216,991)\end{array}$ & $\begin{array}{l}\text { Average length } \\
\text { of stay amongst } \\
\text { all decedents } \\
\text { (days) } \\
(\mathrm{N}=264,754)\end{array}$ \\
\hline \multicolumn{4}{|l|}{ Places of care } \\
\hline Acute care & 18.7 & 10.5 & 12.0 \\
\hline $\begin{array}{l}\text { Complex } \\
\text { continuing } \\
\text { care }\end{array}$ & 1.3 & 3.3 & 2.9 \\
\hline Rehabilitation & 0.6 & 0.3 & 0.4 \\
\hline $\begin{array}{l}\text { Emergency } \\
\text { department }\end{array}$ & 0.8 & 0.7 & 0.7 \\
\hline $\begin{array}{l}\text { Total } \\
\text { institution use }\end{array}$ & 21.4 & 14.8 & 16.0 \\
\hline Home care & 7.7 & 11.4 & 10.8 \\
\hline Total use & 29.1 & 26.3 & 26.8 \\
\hline
\end{tabular}

that would be expected to do worse in the ICU $[15,20]$. Moreover, end-of-life care costs are much more expensive when patients have a greater burden of disease and when they are admitted to the ICU. In addition, a large percentage of the population admitted to critical care at the end of life die in hospital with aggressive care measures taken. When put in the context of our rising healthcare costs [1] and a movement towards aging in place (in the community) [33,34], this represents an area where more work is needed to ensure that only patients who can clearly benefit from critical care receive it at the end of life.

\section{Additional file}

Additional file 1:Table S1. Characteristics and demographics of decedents in the last 90 days of life. Table S2. Databases used to record health care use and costs at the end of life. Description of all databases used to collect data for this study (DOCX $25 \mathrm{~kb}$ )

\section{Acknowledgements}

Not applicable.

\section{Funding}

This research was supported by a research grant from the Ontario Ministry of Health and Long Term Care (MOHLTC) to the Health System Performance Research Network Grant (HSPRN \#06034). This study was also supported by the Institute for Clinical Evaluative Sciences (ICES), which is funded by an annual grant from the Ontario MOHLTC. The views expressed in this paper are the views of the authors and do not necessarily reflect those of the funder. The funders had no influence on the design and conduct of the study, the collection, management, analysis, and interpretation of the data, or the preparation, review, or approval of the manuscript

\section{Availability of data and materials}

The datasets during and/or analyzed during the current study are available from the corresponding author on reasonable request.

\section{Authors' contributions}

All authors contributed significantly to the work. KK and DC contributed to the conception of the paper. KK, PT, MC, and DC contributed to data analysis and interpretation. $\mathrm{KK}, \mathrm{PT}, \mathrm{GD}, \mathrm{BH}$, and $\mathrm{DC}$ contributed to drafting and editing the manuscript. All authors provided final approval of the manuscript.

\section{Competing interests}

The authors declare that they have no competing interests.

\section{Consent for publication}

Not applicable.

\section{Ethics approval and consent to participate}

This study has been approved by the research ethics board at the Institute for Clinical Evaluative Sciences, at Sunnybrook Health Sciences Centre and at Ottawa Hospital Research Institute. No written consent was obtained; all data were encrypted using health card numbers as unique identifiers. Thus all records used were de-identified and anonymized.

\section{Publisher's Note}

Springer Nature remains neutral with regard to jurisdictional claims in published maps and institutional affiliations.

\section{Author details}

${ }^{1}$ University of Ottawa, Ottawa, ON, Canada. ${ }^{2}$ Bruyère Research Institute, Ottawa, ON, Canada. ${ }^{3}$ Ottawa Hospital Research Institute, Ottawa, ON, Canada. ${ }^{4}$ The Ottawa Hospital General Campus, 501 Smyth Road, Ottawa, ON K1H 8L2, Canada.

Received: 12 September 2016 Accepted: 9 May 2017

Published online: 31 May 2017

\section{References}

1. Tanuseputro P, Wodchis WP, Fowler R, et al. The health care cost of dying: a population-based retrospective cohort study of the last year of life in Ontario, Canada. PLoS ONE. 2015:10(3):e0121759.

2. Kaul P, McAlister FA, Ezekowitz JA, et al. Resource use in the last 6 months of life among patients with heart failure in Canada. Arc Intern Med. 2011; 171(3):211-7.

3. Marik PE. The cost of inappropriate care at the end of life implications for an aging population. Am J Hosp Palliat Med. 2015;32(7):703-8.

4. Singal RK, Sibbald R, Morgan B, et al. A prospective determination of the incidence of perceived inappropriate care in critically ill patients. Can Respir J. 2014;21(3):165-70

5. Khandelwal N, Kross EK, Engelberg RA, et al. Estimating the effect of palliative care interventions and advance care planning on ICU utilization: a systematic review. Crit Care Med. 2015:43(5):1102.

6. Huynh TN, Kleerup EC, Wiley JF, et al. The frequency and cost of treatment perceived to be futile in critical care. JAMA Intern Med. 2013;173(20):1887-94.

7. Palda VA, Bowman KW, McLean RF, et al. "Futile" care: do we provide it? Why? A semistructured, Canada-wide survey of intensive care unit doctors and nurses. J Crit Care. 2005;20(3):207-13.

8. Population by year, by province and territory. CANSIM, table 051-0001. Statistics Canada; 2014 Available from: http://www.statcan.gc.ca/tablestableaux/sum-som/l01/cst01/demo02a-eng.htm. Accessed 24 Jan 2016.

9. Angus DC, Barnato AE, Linde-Zwirble WT, et al. Use of intensive care at the end of life in the United States: an epidemiologic study. Crit Care Medicine. 2004:32(3):638-43.

10. Wunsch $\mathrm{H}$, Linde-Zwirble WT, Harrison DA, et al. Use of intensive care services during terminal hospitalizations in England and the United States. Am J Resp Crit Care. 2009;180(9):875-80.

11. Lyngaa $\mathrm{T}$, Christiansen $\mathrm{CF}$, Nielsen $\mathrm{H}$, et al. Intensive care at the end of life in patients dying due to non-cancer chronic diseases versus cancer: a nationwide study in Denmark. Crit Care. 2015;19(1):1

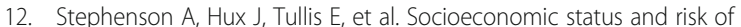
hospitalization among individuals with cystic fibrosis in Ontario, Canada. Pediatr Pulmonol. 2011:46(4):376-84.

13. Austin PC, van Walraven C, Wodchis WP, et al. Using the Johns Hopkins Aggregated Diagnosis Groups (ADGs) to predict mortality in a general adult population cohort in Ontario, Canada. Med Care. 2011;49(10):932. 
14. Wodchis WP, Bushmeneva K, Nikitovic M, et al. Guidelines on person level cost using administrative databases in Ontario. Toronto: Health System Performance Research Network (HSPRN); 2013.

15. Sacanella E, Pérez-Castejón JM, Nicolás JM, et al. Mortality in healthy elderly patients after ICU admission. Intensive Care Med. 2009;35(3):550-5.

16. Peigne V, Somme D, Guérot E, et al. Treatment intensity, age and outcome in medical ICU patients: results of a French administrative database. Ann Intensive Care. 2016;6(1):1-8.

17. Pintado MC, Villa P, Luján J, et al. Mortality and functional status at one-year of follow-up in elderly patients with prolonged ICU stay. Medicina Intensiva (English Edition). 2016:40(5):289-97.

18. Topeli A, Cakir B. Hospital survival of older patients admitted to a medical intensive care unit. Aging Clin Exp Res. 2007;19(1):69-74.

19. Zampieri FG, Colombari F. The impact of performance status and comorbidities on the short-term prognosis of very elderly patients admitted to the ICU. BMC Anesthesiol. 2014;14(1):1.

20. Brinkman S, Bakhshi-Raiez F, Abu-Hanna A, et al. Determinants of mortality after hospital discharge in ICU patients: literature review and Dutch cohort study. Crit Care Med. 2013;41(5):1237-51.

21. Fuchs L, Chronaki CE, Park S, et al. ICU admission characteristics and mortality rates among elderly and very elderly patients. Intensive Care Med. 2012:38(10):1654-61.

22. Yang Y, Yang KS, Hsann YM, et al. The effect of comorbidity and age on hospital mortality and length of stay in patients with sepsis. J Crit Care. 2010;25(3):398-405.

23. Ho KM, Dobb GJ, Lee KY, et al. The effect of comorbidities on risk of intensive care readmission during the same hospitalization: a linked data cohort study. J Crit Care. 2009;24(1):101-7.

24. Norena $\mathrm{M}$, Wong $\mathrm{H}$, Thompson WD, et al. Adjustment of intensive care unit outcomes for severity of illness and comorbidity scores. J Crit Care. 2006; 21(2):142-50.

25. Orwelius L, Nordlund A, Edéll-Gustafsson U, et al. Role of preexisting disease in patients' perceptions of health-related quality of life after intensive care. Crit Care Med. 2005;33(7):1557-64.

26. Garland A, Olafson K, Ramsey CD, et al. Distinct determinants of long-term and short-term survival in critical illness. Intensive Care Med. 2014;40(8):1097-105.

27. Wilson DM, Cohen J, Deliens $L$, et al. The preferred place of last days: results of a representative population-based public survey. J Palliat Care. 2013;16(5):502-8.

28. Fowler R, Hammer M. End-of-life care in Canada. Clin Invest Med. 2013; 36(3):127-32.

29. Heyland DK, Dodek P, Rocker G, et al. What matters most in end-of-life care: perceptions of seriously ill patients and their family members. CMAJ. 2006; 174(5):627-33.

30. Seow H, Barbera L, Pataky R, et al. Does increasing home care nursing reduce emergency department visits at the end of life? A population-based cohort study of cancer decedents. J Pain Symptom Manage. 2016;51(2):204-12.

31. Somogyi-Zalud E, Zhong Z, Hamel MB, et al. The use of life-sustaining treatments in hospitalized persons aged 80 and older. J Am Geriatr Soc 2002;50(5):930-4

32. Bach PB, Schrag D, Begg CB. Resurrecting treatment histories of dead patients: a study design that should be laid to rest. JAMA. 2004;292(22):2765-70

33. Heyland DK, Barwich D, Pichora D, et al. Failure to engage hospitalized elderly patients and their families in advance care planning. JAMA Intern Med. 2013;173(9):778-87.

34. Government of Canada. Thinking about aging in place. Human Resources and Skills Development Canada. 2012. http://www.seniors.gc.ca/eng/ working/fptf/place.shtml. Accessed 5 May 2016.

\section{Submit your next manuscript to BioMed Central and we will help you at every step:}

- We accept pre-submission inquiries

- Our selector tool helps you to find the most relevant journal

- We provide round the clock customer support

- Convenient online submission

- Thorough peer review

- Inclusion in PubMed and all major indexing services

- Maximum visibility for your research

Submit your manuscript at www.biomedcentral.com/submit
Biomed Central 